\title{
Active Site Studies on Muscle Carbonic Anhydrase III ${ }^{a}$
}

\author{
W. R. CHEGWIDDEN \\ Department of Biological Sciences \\ Sheffield City Polytechnic \\ Sheffield, SI IWB, England \\ D. HEWETT-EMMETT and R. E. TASHIAN \\ Department of Human Genetics \\ University of Michigan Medical School \\ Ann Arbor, Michigan 48109
}

\section{INTRODUCTION}

Carbonic anhydrase occurs, in reptiles, birds and mammals, in at least three genetically distinct isozyme forms designated CA I, CA II, and CA III.' The CA III isozymes, which are abundantly present in red skeletal muscle, possess notably low $\mathrm{CO}_{2}$ hydratase and esterase ( $p$-nitrophenyl acetate) activities ${ }^{2,3}$ and are remarkably resistant to inhibition by some sulfonamides ${ }^{3,4}$ when compared with CA I and CA II. CA III isozymes from rabbit, pig and bovine muscle have also been shown to possess a novel low acid phosphatase activity. ${ }^{2}$ These data tempt speculation that the CA III isozymes may have an as yet unknown physiological role other than catalysis of $\mathrm{CO}_{2}$ hydration. The active site structure of the CA III isozymes shows striking differences from those of CA I and CA II. ${ }^{1}$ Of the five putative active site residues unique to CA III and invariant in all CA III isozymes examined, two, at positions 67 and 91 , are arginine.

It has been previously demonstrated that the treatment of bovine and gorilla CA III with butanedione results in the activation of the bicarbonate dehydration reaction, whereas the bovine and human CA I and CA II isozymes were unaffected by similar treatment. ${ }^{5}$ This report is an extension of those studies.

\section{METHODS}

Human CA I and CA II were purified from red cell hemolysates by affinity chromatography.$^{6}$ Human CA III was purified from autopsied psoas major muscle by affinity chromatography and gel filtration ${ }^{7}$ followed by chromatography on DEAE-cellulose. Similar procedures were used in purifying CA III from bovine and chicken skeletal muscle. Bicarbonate dehydration activity was measured using a pH-stat assay system similar to that of Hansen and $\mathrm{Magid}^{8}$ with $1.0 \mathrm{M}$ sulfuric acid as titrant. Assays were performed at $\mathrm{pH} 7.1$ and $2^{\circ} \mathrm{C}$ in a volume of

a Supported by U.S. Public Health Service grant GM 24681 to R.E.T., and a travel grant from Sheffield City Polytechnic to W.R.C. 
$10 \mathrm{ml}$. The reaction mixture comprised $6.7 \mathrm{mM} \mathrm{Na} \mathrm{HPO}_{4}, 6.7 \mathrm{mM} \mathrm{NaH} \mathrm{PO}_{4}, 30$ $\mathrm{m} M \mathrm{NaHCO}_{3}$, and $0.5 \mathrm{~m} M$ EDTA. Esterase activity towards $p$-nitrophenyl acetate $(1 \mathrm{~m} M)$ was measured spectrophotometrically at $348 \mathrm{~nm}$ in $30 \mathrm{~m} M$ sodium diethylmalonate buffer, $\mathrm{pH} 7.2 .^{9}$ Modification of the enzyme with freshly prepared butanedione was performed in the dark at $25^{\circ} \mathrm{C}$ in $50 \mathrm{mM}$ borate buffer, $\mathrm{pH}$ 8.3. These conditions are known to selectively modify arginine residues. ${ }^{10}$ Tryptic digestion of CA III and BD-modified CA III was effected, after preliminary denaturation with $1 M \mathrm{HCl}$ followed by $1 M \mathrm{NaOH}$, by incubation with $2 \%$ w/w trypsin in $0.05 M$ Tris/Cl buffer, $\mathrm{pH} 8.65$, for 16 hours at $37^{\circ} \mathrm{C}$. Tryptic peptides were separated by HPLC and then sequenced and identified by HPLC as described by Hewett-Emmett et al. ${ }^{7}$

\section{RESULTS AND DISCUSSION}

Modification with butanedione caused a pronounced activation of both the bicarbonate dehydration and esterase activities of human and bovine CA III, but only the esterase activity of chicken CA III (TABLE 1). No effect was observed when human CA I and CA II were similarly incubated with butanedione. Low butanedione concentrations gave rapid activation of the bicarbonate dehydration reaction of $70-100 \%$ (FIG. 1). Activation of the esterase activity followed a slower time course and required higher butanedione concentration $(25 \mathrm{mM})$ but produced a greater degree of activation (TABLE 1).

Tryptic digestion and sequence analysis were performed on human CA III (56 $\mu \mathrm{M}$ ) after modification with butanedione: (A) at $2.5 \mathrm{mM}$ concentration for $10 \mathrm{~min}$ at $25^{\circ} \mathrm{C}$ and (B) at $25 \mathrm{mM}$ concentration for $45 \mathrm{~min}$ at $25^{\circ} \mathrm{C}$ and on appropriate controls in the absence of butanedione. The results for (A) showed very little difference from its control apart from a slight increase in a peptide containing amino acids 90-113, suggesting partial modification of Arg-91. In contrast, (B) showed extensive modification compared to its control. Similar peptide analysis indicated modification of arginine residues at positions $39,67,80$ or 89 , and 91 . Position 39 is not arginine in bovine CA III and position 89 is arginine in CA I and CA II as well as CA III. Arg-80, which may have been modified, is not at the active

TARLE 1. Effect of 2,3-Butanedione (BD) on the Activities of Carbonic Anhydrase Isozymes

\begin{tabular}{|c|c|c|}
\hline Isozyme & $\begin{array}{c}\text { Bicarbonate Dehydration } \\
\text { Activity }\end{array}$ & $\begin{array}{c}\text { Ester Hydrolysis Activity } \\
(p \text {-Nitrophenyl Acetate })\end{array}$ \\
\hline Human CA III & Activation ${ }^{a}$ & Activation $^{b}$ \\
\hline Bovine CA III & Activation & Activation \\
\hline Chicken CA III & No effect & Activation $^{c}$ \\
\hline Human CA II & No effect & No effect ${ }^{d}$ \\
\hline Human CA I & No effect & No effect \\
\hline
\end{tabular}

${ }^{a}$ See Figure 1.

${ }^{b}$ Incubation of Human CA III $(56 \mu \mathrm{M})$ with BD (25 $\mathrm{mM}$ ) for 24 hours produced $>5$-fold activation.

${ }^{c}$ Incubation of chicken CA III $(23 \mu \mathrm{M})$ with BD $(25 \mathrm{mM})$ for 24 hours produced $>10$-fold activation.

${ }^{d}$ Similar incubation with BD for 24 hours caused a slight decline in activity. Other conditions were as described in the text. 


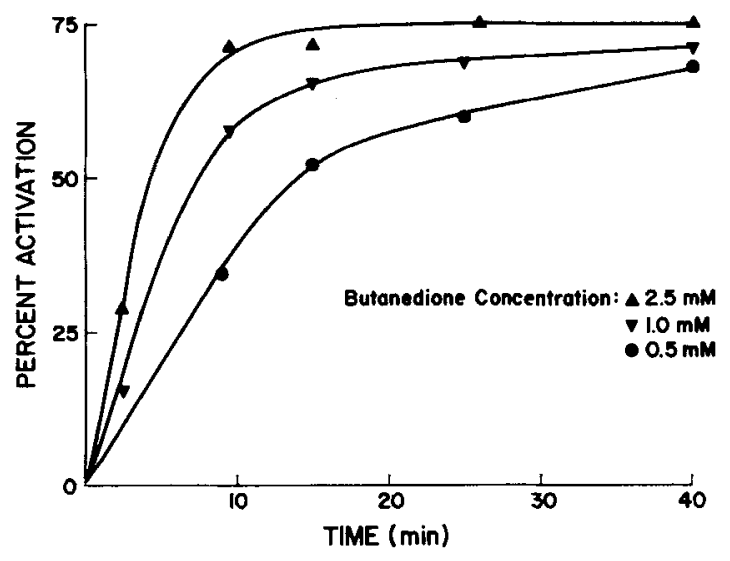

FIGURE 1. Activation of the bicarbonate dehydration activity of human CA III by incubation with 2,3-butanedione in $50 \mathrm{mM}$ borate, $\mathrm{pH} 8.3$ at $25^{\circ} \mathrm{C}$. The enzyme concentration was $13.6 \mu \mathrm{M}$.

site. The results suggest, therefore, that activation is associated with modification of arginyl residues at 67 and 91 , which are unique to CA III. Limited sequencing studies on chicken CA III indicate the presence of either lysine or arginine at positions 67 and $91 .^{1}$ Absence of activation of the bicarbonate dehydration activity of this isozyme by butanedione modification suggests that arginine may not be present in both positions.

\section{REFERENCES}

1. Tashian, R. E., D. Hewett-Emmett \& M. Goodman. 1983. In Isozymes: Current Topics in Biological and Medical Research. Vol. 7: 79-100. Alan R. Liss. New York.

2. Koester, M. K., L. M. Pullan \& E. A. Noltmann. 1981. Arch. Biochem. Biophys. 211: $632-642$.

3. Sanyal, G., E. R. Swenson, N. I. Pessah \& T. H. Maren. 1982. Mol. Pharmacol. 22: $211-220$.

4. Maren, T. H. \& G. Sanyal. 1983. In Annual Review of Pharmacology and Toxicology. Vol. 23: 439-459. Annual Reviews Inc.. Palo Alto, CA.

5. Tashian, R. E., J. T. Johansen \& E. Christiansen. 1980. Fed. Proc. 39: 1303.

6. Osborne, W. R. A. \& R. E. TAshian. 1975. Anal. Biochem. 65: 297-303.

7. Hewett-Emmett, D., R. J. Welty \& R. E. Tashian. 1983. Genetics 105: 409-420.

8. Hansen, P. \& E. Magid. 1966. Scand. J. Clin. Lab. Invest. 18: 21-32.

9. Armstrong, J. MCD., D. V. Myers, J. A. Verpoorte \& J. T. Edsall. 1966. J. Biol. Chem. 241: 5137-5149.

10. Borders, C. L. \& J. F. Riordan. 1975. Biochemistry 14: 4699-4704. 